\title{
Geochemical characterization of aromatic hydrocarbons in crude oils from the Tarim, Qaidam and Turpan Basins, NW China
}

\author{
Zhang Min ${ }^{1,2 *}$ and Paul Philp ${ }^{3}$ \\ ${ }^{1}$ Department of Geochemistry, Yangtze University, Jingzhou, Hubei 434023, China \\ ${ }^{2}$ The Key Laboratory of Oil \& Gas Resources and Exploration Technology, Ministry of Education, Yangtze University, \\ Jingzhou, Hubei 434023, China \\ ${ }^{3}$ School of Geology and Geophysics, University of Oklahoma, Norman, OK 73019, USA
}

(C) China University of Petroleum (Beijing) and Springer-Verlag Berlin Heidelberg 2010

\begin{abstract}
Based on the systematic study of aromatic hydrocarbons in over 100 crude oil samples collected from the Tabei and Tazhong uplifts in the Tarim Basin, the western depression area in the Qaidam Basin and the Tabei depression in the Turpan Basin, the geochemical characteristics of the marine (Tarim Basin), saline lacustrine (Qaidam Basin), and swamp (Turpan Basin) oils were investigated. The marine oils from the Tarim basin are characterized by relatively low abundance of diaromatic hydrocarbons such as biphenyl and naphthalene, and relatively high abundance of triaromatic hydrocarbons including phenanthrene, dibenzothiophene and fluorene. In contrast, the swamp oils from the Turpan Basin are dominated by the highest relative abundance of diaromatic hydrocarbons and the lowest relative abundance of triaromatic hydrocarbons in all the oil samples in this study. The relative abundance of diaromatic and triaromatic hydrocarbons in the saline lacustrine oils from Qaidam Basin is between that in Tarim oils and Turpan oils. Aromatic parameters based on the isomer distributions of dimethylnaphthalenes $(\mathrm{DMN})$, trimethylnaphthalenes (TMN), tetramethylnaphthalenes $(\mathrm{TeMN})$ and methylphenanthrenes (MP), i.e., 1,2,5-trimethylnaphthalene(TMN)/1,3,6-TMN ratio, 1,2,7-TMN/1,3,7TMN ratio, (2,6- +2,7-)-dimethylnaphthalenes (DMN)/1,6-DMN ratio, 1,3,7-TMN/(1,2,5- +1,3,7-)TMN, 1,3,6,7-TeMN/(1,3,6,7- +1,2,5,6- +1,2,3,5-)-TeMN ratio and MP index, may reflect the diversity of organic source input, thermal maturity and depositional environments. In addition, the dibenzothiophenes (DBTs)/fluorenes(Fs) and dibenzofurans (DBFs)/Fs ratios were found to the very useful and effective in determining genetic types of crude oils for the marine, saline lacustrine, and swamp depositional environments, and for oil-oil correlations.
\end{abstract}

Key words: China, Tarim Basin, Qaidam Basin, Turpan Basin, marine oil, saline lacustrine oil, coalderived oil, depositional environment, aromatic hydrocarbons

\section{Introduction}

Aromatic hydrocarbons have attracted considerable attention in recent years as important components ubiquitous in source rocks and crude oils. Research over the last two decades, has led to improved understanding of the sources and significance of polycyclic aromatic hydrocarbons (PAHs) in crude oils and source rocks. The abundance and distribution of PAHs has long been recognized and their structural isomers have also been widely used in assessing the origin of organic matter as well as source rock maturity (Alexander et al, 1983; 1985; 1986; Radke and welte, 1983; Radke et al, 1986; Radke, 1988; Fan et al, 1990; Budzinski et al, 1995; Hughes

*Corresponding author. email. zmjpu@163.com

Received October 25, 2009 et al, 1995; van Aarssen et al, 1999; Huang and Pearson, 1999; Zhang et al, 2005a; 2005b; Li et al, 2005; Grice et al, 2007; Sivan et al, 2008). A number of maturity parameters based on alkylnaphthalenes, methylphenanthrene isomers, methyldibenzothiophenes and dimethyldibenzothiophenes have been developed over the years (Alexander et al, 1985; Radke, 1988; Santamaria, 1988; Chakhmakchev, 1997; van Aarssen et al, 1999). They have also been considered to be the most helpful aromatic hydrocarbon maturity parameters.

The Tarim, Qaidam and Turpan basins in NW China are important petroleum producing basins, representing different depositional environments, including marine, saline lacustrine, and swamp environments. Numerous studies of saturated hydrocarbons in source rocks and crude oils from the Tarim, Qaidam and Turpan basins have been reported (Chen et al, 2001; Huang et al, 1989; 1991a; 1991b; Hanson et al, 
2000; 2001; Li et al, 2000; Zhang et al, 2000; 2005a; 2005b; 2006; Zhu et al, 2005). However, aromatic hydrocarbons are important components in crude oils and source rocks, and can provide significant geochemical information about depositional environments, source input, thermal maturity and oil-source rock correlations. The purpose of this study is to investigate the distribution characteristics and compositional diversities of aromatic hydrocarbons in Tarim, Qaidam and Turpan oils from different depositional environments, and to investigate the geological applications of the geochemical parameters of aromatics.

\section{Geological setting}

The Tarim Basin, with an area of $560,000 \mathrm{~km}^{2}$, is one of the world's largest frontier basins and the largest marine petroleum-producing basin in China (Fig. 1). In the light of its structural framework, the Tarim basin can be divided into three uplifts and four depressions, namely Tabei uplift (North uplift), Tazhong uplift (Central uplift), Tannan uplift (South uplift), Kuche depression, North depression, Southwest depression, and Southeast depression (Li et al, 1996; Chen et al, 2000). Marine oil and gas pools in the Tarim Basin occur widely in the Tabei and Tazhong uplift areas, and the oil is primarily derived from the Middle-Upper Ordovician source rocks (Graham et al, 1990; Zhang et al, 2000; 2005a; 2006). The Middle-Upper Ordovician source rocks consist mainly of argillaceous limestones and marlstone deposited in shelf edge and slope environments, occurring widely in the Tabei and Tazhong uplifts and surrounding areas. These source rock samples have an average total organic carbon (TOC) of 0.43 $\mathrm{wt} \%$, with a maximum TOC value of $6 \mathrm{wt} \%$, and the maturity range of these source rock samples is from mature to overmature stages with respect to oil generation (Hanson et al, 2000; Zhang et al, 2005b). The geochemical characteristics of saturate hydrocarbons in Paleozoic source rocks and crude oils in this basin have been investigated by geologists and petroleum geochemists (Chen et al, 2001; Hanson et al, 2000; 2001; Li et al, 2000; Zhang et al, 2000; 2005a; 2005b; 2006; Zhu et al, 2005). However, due to multiple source rock intervals, multiple charge phases and a variety of modification processes (Xiao et al, 1996; 2000), the aromatic hydrocarbons have attracted considerable attention as important and ubiquitous components in crude oils and source rocks ( $\mathrm{Li}$ et al, 2005).

The Qaidam Basin, with an area of $121,000 \mathrm{~km}^{2}$, is the world's most remote oilfield region at an average elevation of about $3000 \mathrm{~m}$ (Zhu et al, 2005), and the largest saline lacustrine petroleum-producing basin in China (Fig. 1). The basin can be divided into the western depression area (the western Qaidam), the northern broken belts and the eastern depression area. The western part of the Qaidam Basin, with an area of $40,000 \mathrm{~km}^{2}$, accounts for $80 \%-90 \%$ of the petroleum resources and production of the basin (Zhu et al, 2005). Previous studies proposed that the oil in western Qaidam Basin is derived from the lower Ganchaigou Formation which was formed in a saline lacustrine depositional environment (Huang et al, 1989; 1991a; Zhu et al, 2005). The organic matter in these source rocks is mainly type II kerogen, with a major organics input of algae and bacteria and relatively little terrigenous matter (Hanson et al, 2001). On the whole, the maturity range of these source rock samples is from immature to oil-window stages, with Ro values ranging from $0.49 \%$ to $1.17 \%$.

The Turpan Basin, with an area of $53,000 \mathrm{~km}^{2}$, is the largest coal-derived petroleum-producing basin in China (Fig. 1). The basin can be divided into two depressions and one uplift according to its structural framework, namely the Taibei depression, Central uplift and Tainan depression (Li et al, 2001). Previous geochemical studies indicated that most of the oil produced from the Taibei depression shows a



Fig. 1 Location of the Tarim, Qaidam and Turpan basins 
relatively low maturity and characteristics of coal-derived oil. This oil is mainly derived from the Middle-Lower Jurassic coal measures that had high land-plant input, and which were deposited under suboxic conditions similar to swamp and peat environments (Huang et al, 1991b; Cheng and Zhang, 1994; Greene et al, 2004).

\section{Experimental}

\subsection{Samples}

More than 100 oil samples were collected from the Tabei uplift and Tazhong uplift in the Tarim Basin, the western depression in the Qaidam Basin and the Taibei depression in the Turpan Basin. These samples used in this study include: 15 oil samples from a marine depositional environment in the Tarim Basin; 75 oil samples from a saline lacustrine depositional environment in the Qaidam Basin and 23 oil samples from a swamp environment in the Turpan Basin.

\subsection{Methods}

All the oil samples were analyzed by gas chromatographymass spectrometry (GC-MS) in the multiple ion detection mode (MID) to determine the distribution of aromatic hydrocarbons. A HP 5973 mass spectrometer coupled to a HP $6890 \mathrm{GC}$ and equipped with a $30 \mathrm{~m}(0.25 \mathrm{~mm}$ i.d., $0.25 \mu \mathrm{m}$ film thickness) HP-5MS fused silica capillary column was used for the GC-MS analysis. The GC for the analysis was temperature-programmed to be heated for $2 \mathrm{~min}$ at $50^{\circ} \mathrm{C}$, then from $50{ }^{\circ} \mathrm{C}$ to $100{ }^{\circ} \mathrm{C}$ it was heated at a rate of $20^{\circ} \mathrm{C} / \mathrm{min}$, and from $100^{\circ} \mathrm{C}$ to $310^{\circ} \mathrm{C}$ at a rate of $3{ }^{\circ} \mathrm{C} / \mathrm{min}$ and then it was held $15 \mathrm{~min}$ at $310^{\circ} \mathrm{C}$. Helium was used as the carrier gas and the ionization source was operated at $70 \mathrm{eV}$. Identification of peaks in the mass chromatograms was based on mass spectra, retention times and literature comparisons (Cumbers et al, 1987; Radke et al, 1986; Schou and Myhr, 1987).

\section{Results and discussion}

Aromatic hydrocarbons is in the oil samples used in this study, such as biphenyls (with a mass chromatogram of $\mathrm{m} / \mathrm{z} 154,168$ and 182 , BPs), naphthalenes (with a mass chromatogram of $\mathrm{m} / \mathrm{z} 128,142,157,170$ and 184, Ns), phenanthrenes (with a mass chromatogram of $\mathrm{m} / \mathrm{z} 178$, 192, 206and 230, Ps), dibenzothiophenes (with a mass chromatogram of $\mathrm{m} / \mathrm{z} 184,198,212$ and 226, DBTs), dibenzofurans (with a mass chromatogram of $\mathrm{m} / \mathrm{z} 168,182$ and196, DBFs), fluorenes (with a mass chromatogram of $\mathrm{m} / \mathrm{z}$ 166,180 and 196, Fs), chrysenes (with a mass chromatogram of $\mathrm{m} / \mathrm{z} \mathrm{228,} 242$ and 256, CHs), pyrenes (with a mass chromatogram of m/z 202, 216 and 230, PYs) and their alkyl derivatives. The detail geochemical characteristics of aromatic hydrocarbons are described in the following sections.

\subsection{Distribution characteristics of aromatic hydrocarbons}

The distributions of aromatic hydrocarbons in crude oils from the Tarim, Qaidam and Turpan basins exhibited significant differences (Fig. 2). The oil samples from the marine depositional environment in the Tarim
Basin are characterized by the relative content of the aromatic hydrocarbons decreasing in the order of naphthalenes $(\mathrm{Ns})>$ phenanthrenes $(\mathrm{Ps})>$ dibenzothiophenes (DBTs) $>$ dibenzofurans $($ DBFs $)>$ fluorenes $($ Fs $)>$ biphenyls (BPs) $>$ chrysenes $(\mathrm{CHs})>$ pyrenes $(\mathrm{PYs})$, with a relatively low abundance of diaromatics such as biphenyls and naphthalenes, and highest relative abundance of triaromatic hydrocarbons including phenanthrenes, dibenzothiophenes, dibenzofurans and fluorenes in these oil samples. As shown in Table 1, the statistical mean content of total diaromatic hydrocarbons (biphenyl+naphthalene) in marine oils is $49.1 \%(7.81 \%+41.3 \%)$, and the mean content of the total triaromatic hydrocarbons (fluorene+dibenofuran+dibenzoth iophene $)$ is $48.4 \%(22.2 \%+8.61 \%+2.36 \%+15.3 \%)$. The oil samples from the saline lacustrine depositional environment of the Qaidam Basin are characterized by the relative contents of aromatic hydrocarbons decreasing in the order $\mathrm{Ns}>\mathrm{Ps}>\mathrm{BPs}>\mathrm{Fs}>\mathrm{DBTs}>\mathrm{DBFs}>\mathrm{CHs}>\mathrm{PYs}$, with relatively high abundance $(66.0 \%)$ of diaromatic hydrocarbons and relatively high abundance $(31.6 \%)$ of triaromatics. Finally, the oil samples from the swamp depositional environment in the Turpan Basin are characterized by relative contents of aromatic hydrocarbons decreasing in the order of $\mathrm{Ns}>>$ $\mathrm{BPs}>\mathrm{Ps}>\mathrm{DBFs}>\mathrm{Fs}>\mathrm{DBTs}>\mathrm{CHs}>\mathrm{PYs}$, with relatively high abundance (mean value $79.7 \%$ ) of diaromatic hydrocarbons and relatively low abundance (mean value $19.8 \%$ ) of triaromatic hydrocarbons. The relative abundances of chrysene and pyrene in all the oil samples in this study are very much lower than that of other compounds described above.

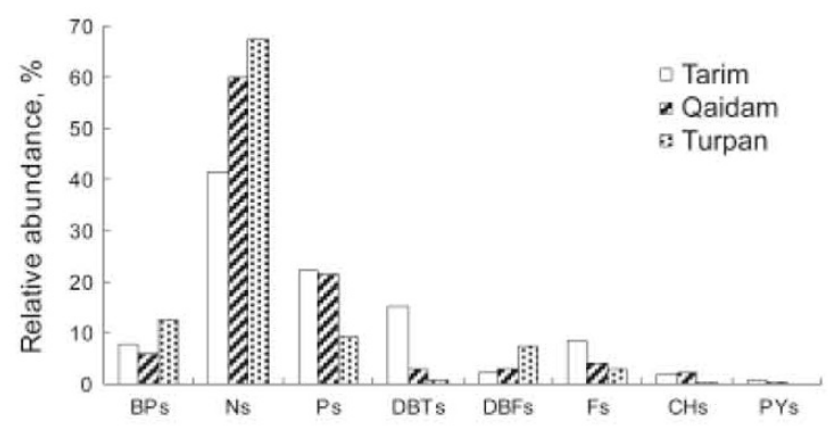

Fig. 2 Relative abundances of polycyclic aromatic hydrocarbons in crude oils from the Tarim, Qaidam and Turpan Basins

BPs-biphenyls, Ns-naphthalenes, Ps-phenanthrenes, DBTs-dibenzothiophenes, DBFs-dibenzofurans, Fs-fluorenes, CHs-chrysenes, PYs-pyrenes

Biphenyl (BP), methylbiphenyls (MBP) and dimethylbiphenyls (DMBP) are present in all the oil samples from the different depositional environments, with the relative concentrations of alkylated biphenyls increasing in the order of $\mathrm{BP}>\mathrm{MBP}>\mathrm{DMBP}$ (Fig. 3). For dimethylbiphenyls, the relative content decreases from $50.3 \%$ (marine oils) to $42.4 \%$ (saline lacustrine oils) to $37.8 \%$ (swamp oils); whereas the relative content of biphenyl increases from $12.3 \%$ (marine oils) to $27.0 \%$ (saline lacustrine oils) to $29.1 \%$ (swamp oils). In addition, the relative abundance of biphenyls to all aromatic hydrocarbons in crude oils from different depositional environments exhibits a relatively wide range 


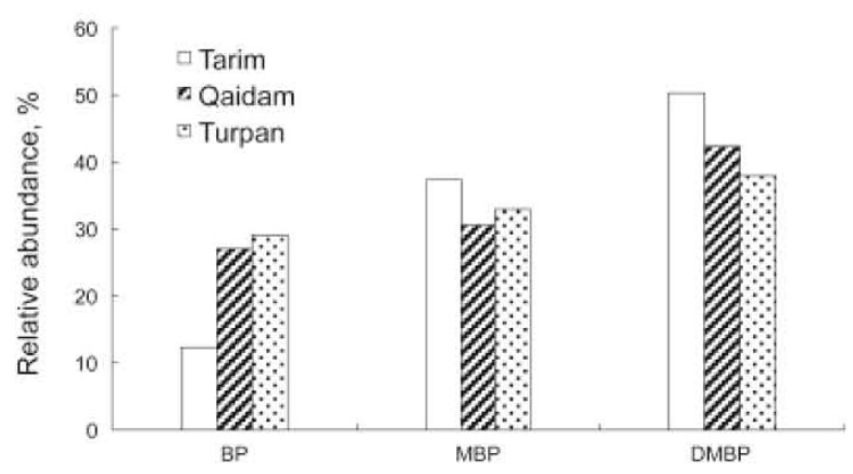

Fig. 3 Distribution of biphenyl and its alkyl derivatives in crude oils from the Tarim, Qaidam and Turpan Basins

BP-biphenyl, MBP-methylbiphenyls, DMBP- dimethylbiphenyls

(Table 1). For example, the mean value of biphenyls in the marine oils is $7.81 \%$, with a range from $4.33 \%$ to $12.9 \%$; the mean value of biphenyls in saline lacustrine oils is $5.85 \%$, with a range from $2.07 \%$ to $13.8 \%$; and the mean value of biphenyls in swamp oils is $12.5 \%$, with a range from $8.53 \%$ to $17.5 \%$. In general, the relative abundance of biphenyls increases going from saline lacustrine to marine to swamp, and from strongly reducing to reducing to suboxic environment, respectively.

Table 1 Relative abundances of aromatic series in crude oils from the Tarim, Qaidam And Turpan Basins

\begin{tabular}{|c|c|c|c|}
\hline \multirow[b]{2}{*}{ Aromatic series } & \multicolumn{3}{|c|}{ Relative abundances, $\%$} \\
\hline & $\begin{array}{c}\text { Marine } \\
\text { (Tarim Basin) }\end{array}$ & $\begin{array}{l}\text { saline lacustrine } \\
\text { (Qaidam Basin) }\end{array}$ & $\begin{array}{c}\text { Swamp } \\
\text { (Turpan Basin) }\end{array}$ \\
\hline \multirow{2}{*}{ Biphenyl } & $4.33-12.90$ & $2.07-13.85$ & $8.53-17.53$ \\
\hline & Mean content 7.81 & 5.85 & 12.49 \\
\hline \multirow{2}{*}{ Naphthalene } & $30.02-49.34$ & $43.09-66.42$ & $56.56-75.62$ \\
\hline & Mean content 41.30 & 60.11 & 67.25 \\
\hline \multirow{2}{*}{ Phenanthrene } & $17.28-28.14$ & $17.81-31.02$ & $1.88-15.76$ \\
\hline & Mean content 22.16 & 21.54 & 9.08 \\
\hline \multirow{2}{*}{ Fluorene } & $5.03-13.32$ & $1.73-7.25$ & $0.9-4.55$ \\
\hline & Mean content 8.61 & 3.99 & 2.91 \\
\hline \multirow{2}{*}{ Dibenzofuran } & $1.66-3.17$ & $1.80-5.03$ & $4.85-8.93$ \\
\hline & Mean content 2.36 & 2.96 & 7.23 \\
\hline \multirow{2}{*}{ Dibenzothiophene } & $8.63-18.47$ & $1.90-5.22$ & $0.16-1.17$ \\
\hline & Mean content 15.3 & 3.13 & 0.61 \\
\hline \multirow{2}{*}{ Chrysene } & $0.59-5.87$ & $1.45-4.48$ & $0.01-0.87$ \\
\hline & Mean content 1.86 & 2.17 & 0.32 \\
\hline \multirow{2}{*}{ Pyrene } & $0.04-3.62$ & $0.05-0.8$ & $0.01-0.23$ \\
\hline & Mean content 0.6 & 0.26 & 0.1 \\
\hline
\end{tabular}

The origin of alkylbiphenyls in crude oils is uncertain but they were derived from different source materials and geological ages (Alexander et al, 1986; Cumbers et al, 1987; Trolio et al, 1999). Li et al (2005) reported that the relatively high abundance of alkylbiphenyls in crude oils, compared to their source rocks, can be related to the effect of migration.
However, the results of this study showed that the relative abundance of biphenyls may be related to kerogen types and/ or depositional environments of source rocks. Crude oils derived from type III kerogen deposited in oxic depositional environments contain relatively high abundance of biphenyls.

Naphthalene (N), methylnaphthalenes (MN), dimethylnaphthalenes (DMN), trimethylnaphthalenes (TMN) and tetramethylnaphthalenes (TeMN) are the most abundant series of aromatic hydrocarbons in all the oil samples in this study. But the relative abundances of alkylated naphthalenes in different types of crude oils reveal significant differences. In marine oils, for example, trimethylnaphthalenes are the most abundant group of naphthalenes (Fig. 4) and their relative contents decrease in the order of $\mathrm{TMN}>\mathrm{DMN}>\mathrm{TeMN}>\mathrm{MN}>\mathrm{N}$. In contrast, in terrestrial oils (Qaidam oils and Turpan oils), the dimethylnaphthalenes are the most abundant group of naphthalenes and their relative contents decrease in the order of $\mathrm{DMN}>\mathrm{MN}>\mathrm{TMN}>\mathrm{N}>\mathrm{TeMN}$. Similarly, the relative abundance of naphthalenes to all the aromatic hydrocarbons in all the crude oil samples in this study exhibits differences. For example, the mean value of naphthalenes in the marine oils is $41.3 \%$, with a range from $30.0 \%$ to $49.3 \%$; the mean value of naphthalenes in the saline lacustrine oils is $60.1 \%$, with a range from $43.1 \%$ to $66.4 \%$; and the mean value of naphthalenes in the swamp oils is $67.2 \%$, with a range from $56.6 \%$ to $75.6 \%$. However, naphthalenes, especially individual trimethylnaphthalenes, have attracted considerable attention due to their widespread appearance in crude oils and source rocks. Previous studies have suggested that TMNs derived from aromatization processes are of special interest, since they are potentially useful as indicator of depositional environments (Strachan et al, 1988). Acidic depositional environments, such as coal swamps, should be favorable to the formation of particular TMNs, whereas deltaic and marine transgressive environments should not be favorable to aromatization, resulting in the preservation of higher plant triterpenoid skeletons. More specifically higher relative abundances of 1,2,7-TMN are found in crude oils and source rocks as a result of the structural degradation of oleananetype triterpenoids derived from higher plant organic matter (Hoffmann et al, 1984; Strachn et al, 1988). Strachn et al

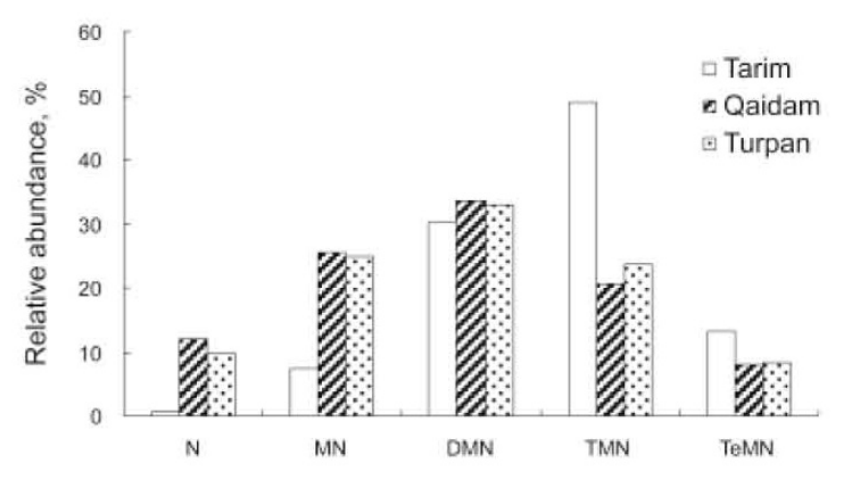

Fig. 4 Distribution of naphthalene and its alkyl derivatives in crude oils from the Tarim, Qaidam and Turpan Basins

$\mathrm{N}$-naphthalene, MN-methylnaphthalene, DMN-dimethylnaphthalene, TMN- trimethylnaphthalene, TeMN-tetramethylnaphthalene 
(1988) reported that source rock samples of Cretaceous age and younger contain enhanced relative abundances of 1,2,5TMN and 1,2,7-TMN, and that older samples containing type III organic matter were found to contain enhanced relative abundances of 1,2,5-TMN and lower relative abundances of 1,2,7-TMN. Source rock samples deposited in marine depositional environments were found to contain lower relative abundances of 1,2,5-TMN and 1,2,7-TMN.

Fig. 5 shows the cross-plot of $1,2,5-\mathrm{TMN} / 1,3,6-\mathrm{TMN}$ vs.1,2,7-TMN/1,3,7-TMN ratios, which is distinctly different in crude oils from different basins. The saline lacustrine oils (from the Qaidam Basin) originating mainly from the lower Ganchaigou Formation $\left(\mathrm{E}_{3}\right)$ show a predominance of 1,2,7-TMN/1,3,7-TMN ratios, with a mean value of 1.57 and a range from 0.93 to 2.29 , and relatively high $1,2,5-\mathrm{TMN} / 1,3,6-\mathrm{TMN}$ ratios, with a mean value of 0.41 and a range from 0.27 to 1.13 . The swamp oils (from the Turpan Basin) originating from Middle-Lower Jurassic-aged coaly strata, which had a large amount of land-plant input, show the highest $1,2,5-\mathrm{TMN} / 1,3,6-\mathrm{TMN}$ ratios, with a mean value of 0.65 and a range from 0.50 to 0.98 , and relatively high 1,2,7-TMN/1,3,7-TMN ratios, with a mean value of 1.23 and a range from 0.97 to 1.61 . Marine oils (from Tarim Basin) originating from the Middle-Upper Ordovician source rocks, which consist mainly of argillaceous limestones and marlstone, show the lowest 1,2,5-TMN/1,3,6-TMN ratios and $1,2,7-\mathrm{TMN} / 1,3,7-\mathrm{TMN}$ ratios, with mean values of 0.21 and 0.99 , respectively. These results agree well with the report of Strachn et al (1988).

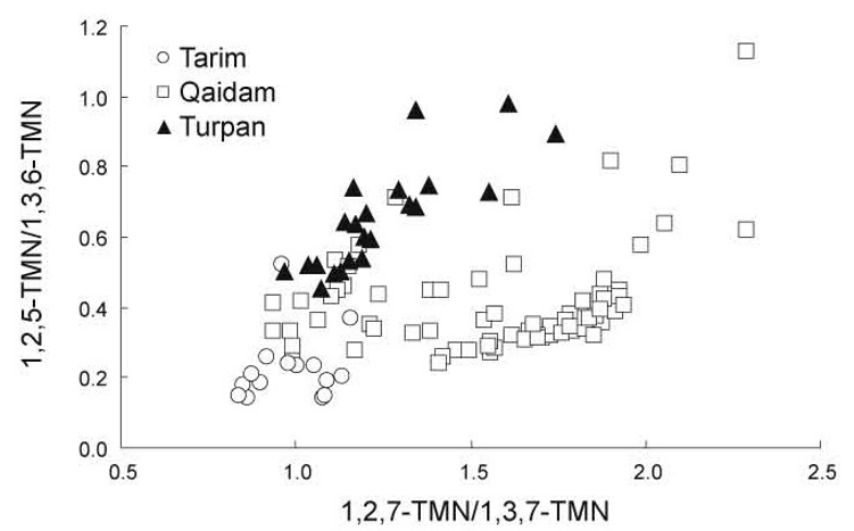

Fig. 5 Cross-plot of 1,2,5-trimethylnaphthalenes(TMN)/1,3,6-TMN vs. 1,2,7-TMN/1,3,7-TMN ratios in crude oils from the Tarim, Qaidam and Turpan Basins

Oleananes, as markers for the angiosperms, provide valuable source and age information when present in oils. The abundance of oleananes in terrigenous oils and sediments may be highly sensitive to changes in early diagenetic conditions. Murray et al (1997) presented evidence that the contact of plant matter with seawater during early diagenesis can enhance the expression of oleananes in a mature sediment or oil. Unfortunately, oleananes are absent or present at a very low content in all the oil samples in this study, so we were unable to derive any reliable information from these compounds.
Phenanthrene (P), and its alkylated analogues, including methylphenanthrene (MP), dimethylphenanthrene (DMP), trimethylphenanthrene (TMP), is the second most abundant series of aromatic compounds in the oil samples from the Tarim and Qaidam basins but not from the Turpan basin. The relative contents of the alkylated phenanthrenes in the crude oils from the Tarim and Qaidam basins are very similar, decreasing in the order of $\mathrm{DMP}>\mathrm{MP}>\mathrm{TMP}>\mathrm{P}$ (Fig. 6). The relative abundance of the phenanthrenes in the oils from the Tarim and Qaidam basins are also very similar, with mean values of $22.2 \%$ and $21.5 \%$, respectively. However, the relative contents of alkylated phenanthrenes in the crude oils from the Turpan basin decrease in the order of DMP $>$ MP $>$ P $>$ TMP, and the relative abundances of phenanthrenes in all aromatic hydrocarbon series are relatively low, with a mean value of only $9.08 \%$.

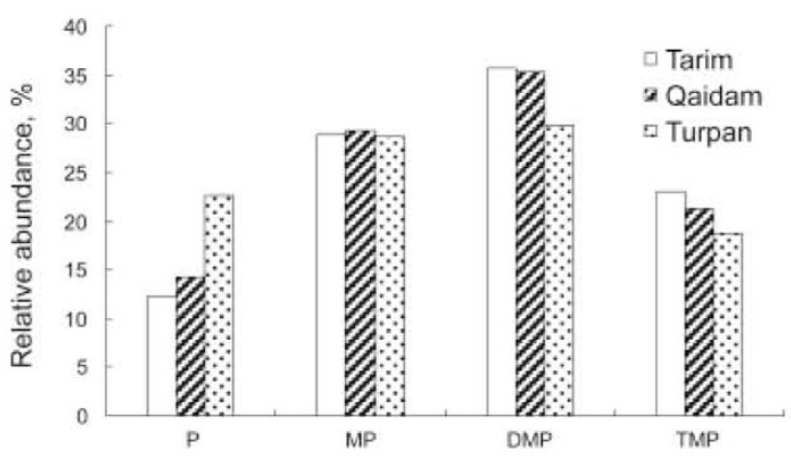

Fig. 6 Distribution of phenanthrene and its alkyl derivatives in crude oils from the Tarim, Qaidam and Turpan Basins

From the above result it can be seen that the relative contents of aromatic compounds are different in the crude oils from the three basins. However, for the oils from the same basin, the relative contents of alkylated homologues show little difference and are even fairly close to some extent.

\subsection{Distribution of fluorenes, dibenzofurans and dibenzothiophenes}

Fluorene, dibenzofuran, dibenzothiophene, and their alkylated analogues, are widely distributed in different types of crude oils and source rocks. Even though these compounds have similar basic skeletons, namely a five-membered ring connecting with two aromatic rings, the relative abundances of fluorenes, dibenzofurans and dibenzothiophenes in oils and source rock samples from different depositional environments are distinctly different. Fan et al (1990) reported that the contents of fluorenes and dibenzofurans in crude oils and source rocks from the swamp depositional environment are higher than those in the marine oils and carbonate source rocks. The content of dibenzothiophenes in marine oils and carbonate source rocks are higher than those in the crude oils and source rocks from the swamp depositional environment. Therefore, the relative amounts of fluorene, dibenzofuran, dibenzothiophene and their alkylated analogues have been used as an indicator of source depositional environment (Fan et al, 1990; Li et al, 2005).

As shown in Fig. 2 and Table 1, the relative abundance of 
dibenzothiophenes in all aromatic hydrocarbons of the crude oils from three different depositional environments decrease in the order of marine $>$ saline lacustrine $>$ swamp, with mean values of $15.3 \%, 3.13 \%$ and $0.61 \%$, respectively. The relative abundance of dibenzofurans in all aromatic hydrocarbons of crude oils formed in various depositional environments increases in the order of marine $<$ saline lacustrine $<$ swamp, with mean values of $2.36 \%, 2.96 \%$ and $7.23 \%$, respectively. Similar distribution of dibenzofurans in source rocks from the marine, lacustrine and swamp depositional environments in the Tarim basin was reported by Li et al (2005). In addition, relatively low abundance of fluorenes are found in the terrestrial oils, with a mean value of $2.91 \%$ in swamp oils from the Turpan Basin, and mean value of $3.99 \%$ in saline lacustrine oils from the Qaidam Basin; and relatively high abundance of fluorenes is found in marine oils from the Tarim Basin, with a mean value of $8.61 \%$.

The relative abundance of fluorenes, dibenzofurans and dibenzothiophenes in the crude oils in this study are plotted in Fig. 7. The crude oils from the three different depositional environments are separated into three different domains, indicating three distribution patterns. In marine oils from the Tarim Basin, the relative contents of fluorenes, dibenzofurans and dibenzothiophenes increase in the order of fluorenes< dibenzofurans $<$ dibenzothiophenes. The relative content of dibenzothiophenes has a mean value of $57.9 \%$, with a range from $48.9 \%$ to $64.8 \%$; fluorenes, the second most abundant series, have a mean value of relative content of $32.7 \%$, with a range from $22.7 \%$ to $42.5 \%$; and dibenzofurans have the lowest relative content with a mean value of $9.31 \%$ and a rang from $5.53 \%$ to $15.8 \%$. In the saline lacustrine oils from the Qaidam Basin, the relative contents of fluorenes, dibenzofurans and dibenzothiophenes decrease in the order of fluorenes $>$ dibenzothiophenesdibenzofurans. The relative content of fluorenes has a mean value of $40.0 \%$ with a range from $23.2 \%$ to $55.9 \%$, whereas the relative contents of dibenzothiophenes and dibenzofurans are very similar, with

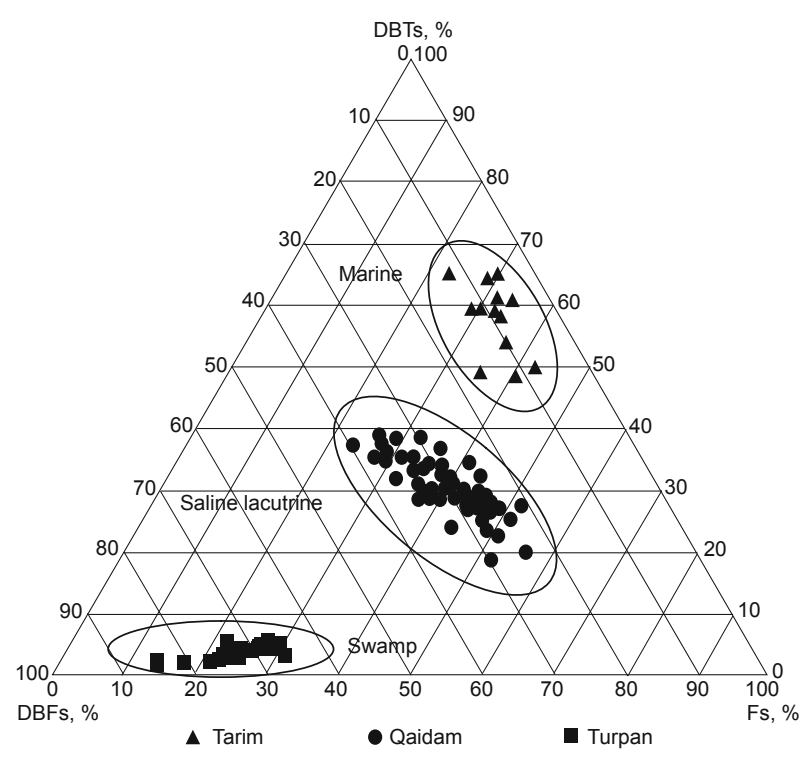

Fig. 7 Triangular plot of relative content of fluorenes(Fs), dibenzofurans(DBFs) and dibenzothiophenes(DBTs) in crude oils from the Tarim, Qaidam and Turpan Basins mean values of $30.6 \%$ and $29.4 \%$, respectively. In contrast, for the swamp oils from the Turpan Basin, the relative contents decrease in the order of dibenzofurans $>$ fluorenes $>$ dibenzothiophenes. Dibenzofurans has the highest relative content, with a mean value of $72.1 \%$ and a range from $65.7 \%$ to $84.4 \%$. Fluorenes, the second abundant series, has a mean value of relative content of $24.0 \%$, with a range from $13.2 \%$ to $30.8 \%$, whereas dibenzothiophenes has the lowest relative content, with a mean value of $3.97 \%$ and a range from $1.97 \%$ to $5.89 \%$.

The cross-plot of dibenzothiophenes/dibenzofurans ratio vs. fluorenes/dibenzofurans ratio in Fig. 8 shows the crude oils from the three basins are different. This is attributed to their different depositional environments. The high dibenzothiophenes/dibenzofurans ratios $(>2)$, and the high fluorenes/dibenzofurans ratios $(>2)$ in marine oils from the Tarim Basin reveal the action of microorganisms in an anoxic depositional environment because of the higher $\mathrm{H}_{2} \mathrm{~S}$ content. The low dibenzothiophenes/dibenzofurans ratios $(<0.5)$, and low fluorenes/dibenzofurans ratios $(>0.5)$ in swamp oils from the Turpan Basin demonstrate the oxic depositional environment of terrestrial organic material. The saline lacustrine oils from the Qaidam Basin have relatively high dibenzothiophenes/dibenzofurans ratios (0.5-2) and fluorenes/ dibenzofurans ratios $(0.5-2)$, reflecting the high salinity and anoxic characteristics of a saline lacustrine depositional environment.

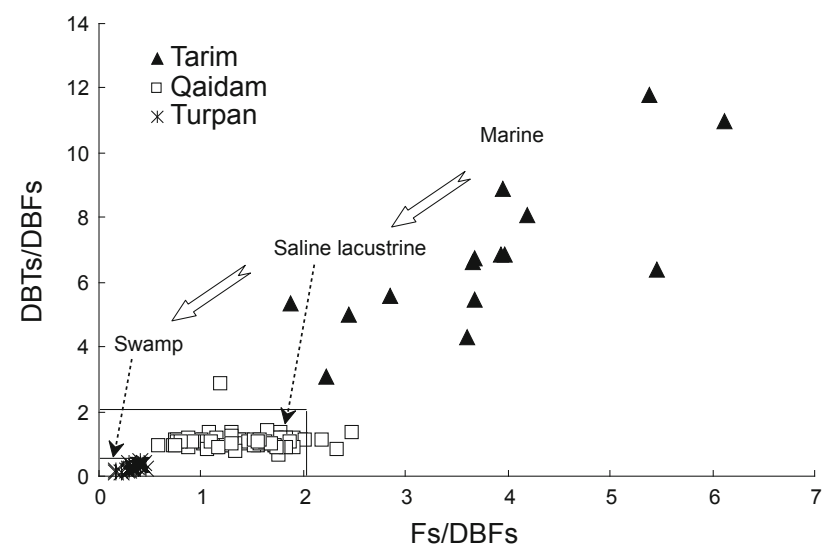

Fig. 8 Cross-plot of dibenzothiophenes(DBTs)/dibenzofurans(DBFs) vs fluorenes(Fs)/dibenzofurans(DBFs) ratios in crude oils from the Tarim, Qaidam and Turpan Basins

Hughes et al (1995) proposed that the ratios of dibenzothiophene/phenanthrene vs. pristine/phytane can be used for distinguishing source rock paleodepositional environments. As shown in Fig. 9, the marine oils from the Tarim Basin mainly fall into source rocks zone associated with marine carbonate, and the saline lacustrine oils from the Qaidam Basin fall into source rocks zone associated with lacustrine hypersaline, whereas the swamp oils from the Turpan Basin are related to fluvio-deltaic shale and coal. Therefore, the ratio of dibenzothiophene/phenanthrene is a good indictor in estimating the reduced sulfur for incorporation into organic matter, and can be used to discriminate redox conditions of different depositional environments. 


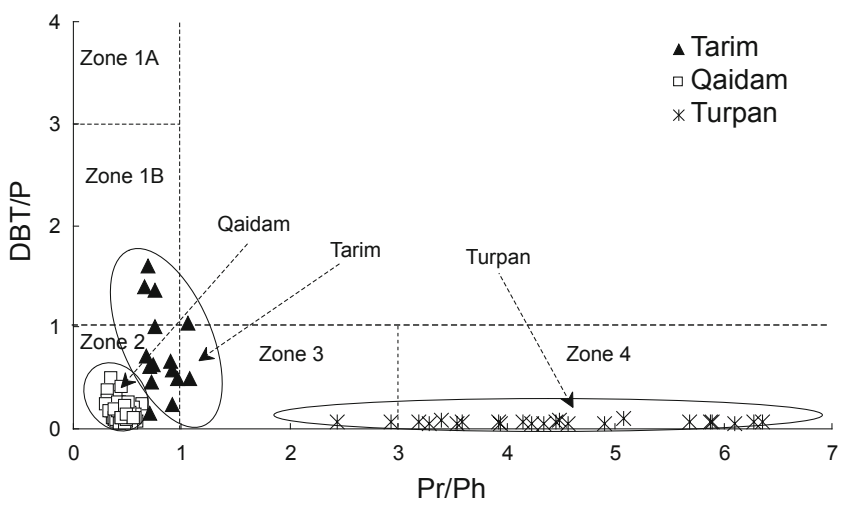

Fig. 9 Cross-plot of dibenzothiophene/phenanthrene (DBT/P) and pristane/phytane $(\mathrm{Pr} / \mathrm{Ph})$ rations in crude oils from the Tarim, Qaidam and Turpan Basins

Modified from Hughes et al (1995), Zone 1A: marine carbonate; Zone 1B: marine carbonate and marl; Zone 2: lacustrine hypersaline; Zone 3: marine shale and other lacustrine; Zone 4: fluvio-deltaic shale and coal

\subsection{Maturity parameters based on aromatic hydrocarbons}

Maturity parameters based on isomer distribution of alkylated aromatic hydrocarbons, such as dimethylnaphthalenes (Alexander et al, 1983, 1986), trimethylnaphthalenes and tetramethylnaphthalenes (Radke et al, 1986; van Aarssen et al, 1999), and methylphenanthrenes (Radke and Welte, 1983), are related to the relative thermal stability of these compounds. $\beta$-substituted isomers are less strained and more stable than $\alpha$-substituted counterparts. A number of aromatic maturity parameters, such as (1) DNRx (Alexander et al, 1985), i.e. (2,6- +2,7-)-DMN/1,6-DMN ratio, (2) TMNr (van Aarssen et al, 1999), i.e. 1,3,7-TMN/ (1,2,5- +1,3,7-)-TMN ratio, (3) TeMNr (van Aarssen et al, 1999), i.e. 1,3,6,7-TeMN/(1,3,6,7- +1,2,5,6- +1,2,3,5-)-TeMN ratio, and (4) Methylphenanthrene Index [MPI1 $=1.5 \times(2-$ $\mathrm{MP}+3-\mathrm{MP}) /(\mathrm{P}+1-\mathrm{MP}+9-\mathrm{MP})]$, have been widely used as molecular maturity parameters and can provide additional assessments of petroleum maturity.

The maturity trends of DNRx and TMNr ratios in crude oils from different depositional environments are shown in Fig. 10. The positive correlation between the DNRx and the TMNr ratios for crude oils from a single basin indicates the validity of dimethylnaphthalene and trimethylenaphthalene maturity ratios. On the other hand, the variations in the linear relationship between the DNRx and MNRr ratios for crude oils from different depositional environments suggest that their maturity parameters are influenced by the types of organic matter. As shown in Table 2, Tarim oils have the highest DNRx and TMNr values, indicating their high maturity level. The DNRx and TMNr values of the Tarim oils are in the range of $0.97-1.82$ and $0.70-0.82$, respectively. In addition, the MPI1 values of the Tarim oils are in the range from 0.66 to 0.94 , and the $\% \mathrm{Rc}$ values calculated by using the equation of $\% \mathrm{Rc}=0.6 \times \mathrm{MPI} 1+0.4$ (Radke and Welte, 1983) are in the range of $0.77-0.97$. The DNRx and TMNr values of the Qaidam oils and Turpan oils are very similar. The DNRx and TMNr values of the Qaidam oils are in the range of 0.681.39 and $0.34-0.73$, respectively, while the DNRx and TMNr values of the Turpan oils are in the range of 0.83-1.66 and $0.47-0.68$, respectively. And the MPI1 and \% Rc values are also similar, with the MPI1 and \%Rc of Qaidam oils in the range of $0.37-0.76$ and $0.64-0.80$, respectively and the MPI1 and $\% \mathrm{Rc}$ for the Turpan oils in the range of $0.24-0.66$ and $0.54-0.83$, respectively. In general, the values of the aromatic maturity parameter of Qaidam and Turpan oils in this study are lower than those of Tarim oils.

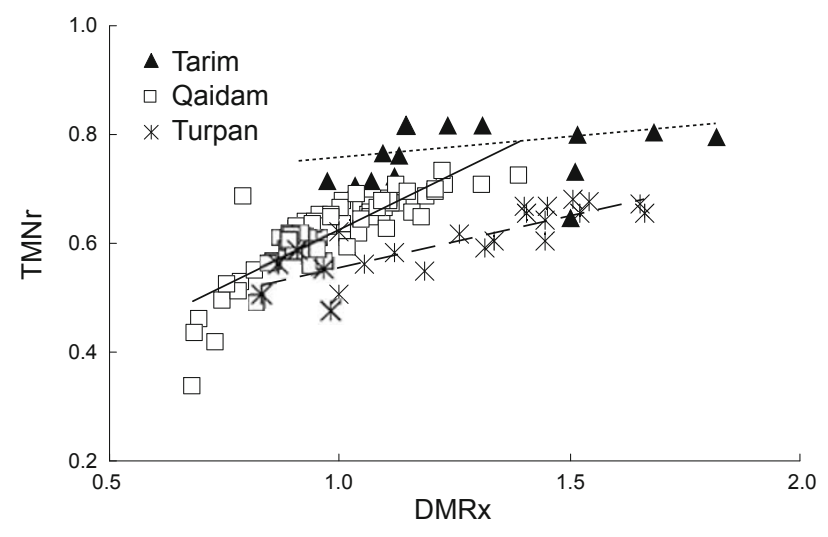

Fig. 10 Cross-plot of DMRx and TMNr ratios in crude oils from the Tarim, Qaidam and Turpan Basins

DMRx, (2,6- +2,7-)-dimethylnaphthalene(DMN)/1,6-DMN; TMNr, 1,3,7-t rimethylenaphthalene(TMN)/(1,2,5- +1,3,7-)-TMN

\section{Conclusions}

The relative abundance of the diaromatic and triaromatic hydrocarbons in crude oils reveals the diversity of the organic matter source input and depositional environments. The relative abundance of biphenyls increases in the order saline lacustrine $<$ marine $<$ swamp, the naphthalenes and the dibenzofurans contents decrease in the order marine $<$ saline lacustrine $<$ swamp, the phenanthrenes, dibenzothiophenes and fluorenes contents increase in the order marine $>$ saline lacustrine $>$ swamp.

The significant differences of the relative abundances in the dibenzothiophene series, dibenzofuran series and fluorene series from Tarim, Qaidam, and Turpan oils, reveal the relative concentrations of those aromatic hydrocarbon compounds mainly result from depositional environments. Moreover, in this paper, aromatic parameters based on the dibenzothiophenes/fluorenes vs. dibenzofurans/fluorenes ratios have been proposed. Our studies indicate those parameters are very useful and effective for oil-oil correlation and characterization of oil types from the marine, saline lacustrine, and swamp depositional environments.

The ratios of alkylated naphthalenes and alkylated phenanthrenes in Tarim, Qaidam and Turpan oils from the marine, saline lacustrine and swamp depositional environments are still effective aromatic maturity parameters. The thermal maturity of the Tarim oils is higher than those of the Qaidam oils and Turpan oils. 
Table 2 Aromatic maturity parameters for crude oils from the Tarim, Qaidam and Turpan Basins

\begin{tabular}{|c|c|c|c|c|c|c|c|c|}
\hline Basin & Well & Depth, m & Strata & DNRx & $\mathrm{TNRr}$ & TeNRr & MPI1 & Rc, $\%$ \\
\hline Tarim & TZ58 & 4710.6 & $\mathrm{O}$ & 1.03 & 0.70 & 0.78 & 0.66 & 0.80 \\
\hline Tarim & TZ62-2 & 4773.53-4825 & $\mathrm{O}$ & 0.97 & 0.71 & 0.82 & 0.66 & 0.80 \\
\hline Tarim & TZ621 & $4851.1-4885$ & $\mathrm{O}$ & 1.12 & 0.72 & 0.82 & 0.66 & 0.80 \\
\hline Tarim & TZ82 & $5349.52-5385$ & $\mathrm{O}$ & 1.15 & 0.82 & 0.88 & 0.73 & 0.84 \\
\hline Tarim & TZ82 & $5430.00-5487$ & $\mathrm{O}$ & 1.14 & 0.81 & 0.88 & 0.72 & 0.83 \\
\hline Tarim & TZ821 & $5212.64-5250.2$ & $\mathrm{O}$ & 1.10 & 0.77 & 0.85 & 0.62 & 0.77 \\
\hline Tarim & LG13 & $5544-5626$ & $\mathrm{O}$ & 1.82 & 0.80 & 0.83 & 0.85 & 0.91 \\
\hline Tarim & LG19 & $5419-5460$ & $\mathrm{O}$ & 1.50 & 0.65 & 0.69 & 0.73 & 0.84 \\
\hline Tarim & LG38 & $5619.38-5740$ & $\mathrm{O}$ & 1.51 & 0.73 & 0.71 & 0.80 & 0.88 \\
\hline Tarim & LN63 & $5806.24-5870$ & $\mathrm{O}$ & 1.69 & 0.81 & 0.78 & 0.73 & 0.84 \\
\hline Tarim & LN63 & $5957-6070$ & $\mathrm{O}$ & 1.52 & 0.80 & 0.77 & 0.71 & 0.83 \\
\hline Tarim & LN621 & $5720.8-5785.5$ & $\mathrm{O}$ & 1.24 & 0.82 & 0.82 & 0.85 & 0.91 \\
\hline Tarim & LN631 & 5902.88-5990 & $\mathrm{O}$ & 1.31 & 0.82 & 0.83 & 0.94 & 0.97 \\
\hline Qaidam & Y01-1 & $3633.2-3822.6$ & $\mathrm{E}_{3}{ }^{1}$ & 0.68 & 0.34 & 0.45 & 0.37 & 0.64 \\
\hline Qaidam & Y604 & $1768.2-1837.8$ & $\mathrm{~N}_{1}$ & 1.07 & 0.66 & 0.64 & 0.70 & 0.82 \\
\hline Qaidam & H107 & $2792.60-2887.40$ & $\mathrm{E}_{3}{ }^{1}$ & 0.76 & 0.52 & 0.49 & 0.53 & 0.73 \\
\hline Qaidam & HN1-6 & $997.8-1149.7$ & $\mathrm{~N}_{1}$ & 0.93 & 0.61 & 0.66 & 0.66 & 0.80 \\
\hline Qaidam & HN6-1 & $625-1253.8$ & $\mathrm{~N}_{2}{ }^{1}-\mathrm{N}_{1}$ & 0.92 & 0.63 & 0.67 & 0.65 & 0.80 \\
\hline Qaidam & Q4-6 & $742.7-878.3$ & $\mathrm{E}_{3}^{2}$ & 0.90 & 0.60 & 0.63 & 0.62 & 0.78 \\
\hline Qaidam & QZ19 & 1094.6-1209.8 & $\mathrm{E}_{3}{ }^{1}$ & 0.93 & 0.61 & 0.62 & 0.64 & 0.79 \\
\hline Qaidam & SZ11 & $1289-1289.8$ & $\mathrm{~N}_{1}$ & 0.91 & 0.60 & 0.64 & 0.67 & 0.81 \\
\hline Qaidam & $\mathrm{NC} 2$ & $1498.0-1598.4$ & $\mathrm{~N}_{2}{ }^{1}$ & 1.31 & 0.71 & 0.67 & 0.73 & 0.84 \\
\hline Qaidam & W3-2 & $1410.5-1412.3$ & $\mathrm{~N}_{2}^{1}$ & 1.39 & 0.73 & 0.68 & 0.76 & 0.85 \\
\hline Qaidam & YD118 & $3525.0-3539.2$ & $\mathrm{E}_{3}{ }^{1}$ & 0.95 & 0.59 & 0.58 & 0.63 & 0.79 \\
\hline Qaidam & Y II 255 & $1009-1068.5$ & $\mathrm{~N}_{1}$ & 1.13 & 0.71 & 0.66 & 0.71 & 0.83 \\
\hline Qaidam & YX3 & $1381.2-1390$ & $\mathrm{E}_{3}^{2}$ & 0.89 & 0.60 & 0.62 & 0.59 & 0.77 \\
\hline Turpan & HT1 & $1375-1400.2$ & $\mathrm{~J}_{2} \mathrm{~s}$ & 1.33 & 0.61 & 0.59 & 0.57 & 0.74 \\
\hline Turpan & HT2 & 2228 & $\mathrm{~J}_{2} \mathrm{~s}$ & 0.91 & 0.59 & 0.60 & 0.40 & 0.64 \\
\hline Turpan & L1 & $2677-2687$ & $\mathrm{~J}_{2} \mathrm{~s}$ & 1.18 & 0.55 & 0.48 & 0.51 & 0.71 \\
\hline Turpan & QD3 & $3382-3434$ & $\mathrm{~J}_{2} \mathrm{X}$ & 0.98 & 0.47 & 0.48 & 0.35 & 0.61 \\
\hline Turpan & HX5 & $653-669$ & $\mathrm{~J}_{2} \mathrm{~s}$ & 1.45 & 0.67 & 0.67 & 0.66 & 0.78 \\
\hline Turpan & W5 & $2410.2-2424.4$ & $\mathrm{~J}_{2} \mathrm{~S}$ & 1.66 & 0.65 & 0.65 & 0.56 & 0.74 \\
\hline Turpan & WX1 & 2926.6-2938 & $\mathrm{J}_{2} \mathrm{x}$ & 1.52 & 0.65 & 0.65 & 0.47 & 0.68 \\
\hline Turpan & WX3 & $2314-2323$ & $\mathrm{~J}_{2} \mathrm{~s}$ & 1.65 & 0.67 & 0.65 & 0.55 & 0.73 \\
\hline Turpan & SA1 & $3087-3090$ & $\mathrm{~J}_{2} \mathrm{X}$ & 0.83 & 0.50 & 0.52 & 0.45 & 0.67 \\
\hline Turpan & PB1 & $3467.5-3473.5$ & $\mathrm{~J}_{2} \mathrm{~S}$ & 1.45 & 0.64 & 0.64 & 0.60 & 0.76 \\
\hline Turpan & PB101 & 3833.9 & $\mathrm{~J}_{2} \mathrm{x}$ & 0.87 & 0.56 & 0.59 & 0.24 & 0.54 \\
\hline Turpan & PB101 & $3453.9-3460.8$ & $\mathrm{~J}_{2} \mathrm{~S}$ & 1.41 & 0.65 & 0.64 & 0.60 & 0.76 \\
\hline Turpan & SH102 & $2366.5-2370.9$ & $\mathrm{~J}_{2} \mathrm{q}$ & 1.51 & 0.68 & 0.67 & 0.72 & 0.83 \\
\hline
\end{tabular}

Notes: DMRx, (2,6- +2,7-)-DMN/1,6-DMN; TMNr, 1,3,7-TMN/(1,2,5- +1,3,7-)-TMN; TeMNr, 1,3,6,7-TeMN/ $(1,3,6,7-+1,2,5,6-+1,2,3,5-)-\mathrm{TeMN} ; \mathrm{MPI} 1,1.5 \times(2-\mathrm{MP}+3-\mathrm{MP}) /(\mathrm{P}+1-\mathrm{MP}+9-\mathrm{MP}) ; \mathrm{Rc} \%, 0.6 \times \mathrm{MPI} 1+0.4$ 


\section{Acknowledgements}

This study is funded by the National Natural Science Foundation of China (Grant No. 40973041). The authors thank Hu Guoyi, Wang Zhiyong and Peng Dehua for sample collection and useful discussion.

\section{References}

Alexander R, Cumbers K M and Kagi R I. Alkylbiphenyls in ancient sediments and petroleums. In: Leythaeuser D and Rulkotter J. (Eds.). Advances in Organic Geochemistry, 1985, Organic Geochemistry. 1986. 10: $841-845$

Alexander R, Kagi R I and Sheppard P N. Relative abundance of dimethylnaphthalene isomers in crude oils. Chromatography. 1983. 267: $367-372$

Alexander R, Kagi R I, Rowland S J, et al. The effects of thermal maturity on distributions of dimethylnaphthalenes and trimethylnaphthalenes in some ancient sediments and petroleums. Geochim. Cosmochim. Acta. 1985. 49: 385-395

Budzinski H, Garrigues P, Connan J, et al. Alkylated phenanthrene distributions as maturity and origin indicators in crude oils and rock extracts. Geochimica et Cosmochimica Acta. 1995. 59: 2043-2056

Chakhmakchev A, Suzuki M and Takayama K. Distribution of alkylated dibenzothiophenes in petroleum as a tool for maturity assessments. Organic Geochemistry. 1997. 26: 483-490

Chen J F, Xu Y C and Huang D F. Geochemical characteristics and origin of natural gas in Tarim basin, China, American Association of Petroleum Geologists Bulletin. 2000. 84: 591-606

Chen J P, Qin Y and Huff B G, et al. Geochemical evidence for mudstone as the possible major oil source rock in the Jurassic Turpan Basin, Northwest China. Organic Geochemistry. 2001. 32: 1103-1125

Cheng K M and Zhang C F. Study on coal generated oil in TurpanHarmi basin. Science in China (Science B). 1994. 24: 1216-1222 (in Chinese)

Cumbers K M, Alexander R and Kagi R I. Methylbiphenyl, ethylbiphenyl and dimethylbiphenyl isomer distributions in some crude oils. Geochimica et Cosmochimica Acta. 1987. 51: 3105-3111

Fan P, Philp R P, Li Z X, et al. Geochemical characteristics of aromatic hydrocarbons of crude oils and source rocks from different sedimentary environments. Organic Geochemistry. 1990. 16: 427 435

Graham S A, Brassell S, Carroll A R, et al. Characteristics of selected petroleum source rocks, Xianjiang Uygur autonomous region, Northwest China. American Association of Petroleum Geologists Bulletin. 1990. 74: 493-512

Greene T J, Zinniker D, Moldowan M, et al. Controls of oil family distribution and composition in nonmarine petroleum systems: A case study from the Turpan-Hami basin, northwestern China. American Association of Petroleum Geologists Bulletin. 2004. 88: 447-481

Grice K, Nabbefeld B and Maslen E. Source and significance of selected polycyclic aromatic hydrocarbons in sediments (Hovea-3 well, Perth Basin, Western Australia) spanning the Permian-Triassic boundary. Organic Geochemistry. 2007. 38: 1795-1803

Hanson A D, Ritts B D, Zinniker D, et al. Upper Oligocene lacustrine source rocks and petroleum systems of the northern Qaidam basin, northwest China. American Association of Petroleum Geologists Bulletin. 2001. 85: 601-619

Hanson A D, Zhang S C, Moldowan J M, et al. Molecular organic geochemistry of the Tarim Basin, northwest China. American Association of Petroleum Geologists Bulletin. 2000. 84: 1109-1128

Hoffmann C F, Mackenzie A S, Lewis C A, et al. A biological marker study of coals, shales and oils from the Mahakam Delta, Kalimantan, Indonesia. Chemical Geology. 1984. 42: 1-23
Huang D F, Zhang D J and Huang X. Tertiary oil source correlation in the Qaidam basin. Acta Sedimentol. Sinica. 1989. 7: 1-14 (In Chinese)

Huang D F, Zhang D J, Huang X, et al. Maturation sequence of Tertiary crude oils in the Qaidam basin and its significance in petroleum resource assessment. J. Southeast Asian Earth Science. 1991a. 5: 359-366

Huang D F, Zhang D, Li J, et al. Hydrocarbon genesis of Jurassic coal measures in the Turpan Basin, China. Organic Geochemistry. 1991b. 17: $827-838$

Huang $\mathrm{H}$ P and Pearson M J. Source rock palaeoenvironments and controls on the distribution of dibenzothiophenes in lacustrine crude oils, Bohai Bay Basin, East China. Organic Geochemistry. 1999. 30: 1455-1470

Hughes W B, Holba A G and Dzou L I P. The ratios of dibenzothiophene to phenanthrene and pristane to phytane as indicators of depositional environment and lithology of petroleum source rocks. Geochimica et Cosmochimica Acta. 1995. 59: 3581-3598

Li D S, Liang D G, Jian C Z, et al. Hydrocarbon accumulations in the Tarim Basin, China. American Association of Petroleum Geologists Bulletin. 1996. 80: 1587-1603

Li J G, Philp R P, Meng Z F, et al. Aromatic compounds in crude oils and source rocks and their application to oil-source rock correlations in the Tarim basin, NW China. Journal of Asian Earth Sciences. 2005. 25: 251-268

Li M W, Bao J P, Lin R Z, et al. Revised models for hydrocarbon generation, migration and accumulation in Jurassic coal measures of the Turpan basin, NW China. Organic Geochemistry. 2001. 31: 11271151

Li M W, Xiao Z Y, Snowdon L, et al. Migrated hydrocarbons in outcrop samples: Revised petroleum exploration directions in the Tarim Basin. Organic Geochemistry. 2000. 31: 599-603

Murray A P, Sosrowidjojo I B, Alexander R, et al. Oleananes in oils and sediments: Evidence of marine influence during early diagenesis. Geochemica et Cosmochimica Acta. 1997. 61: 1261-1276

Radke M and Welte D H. The methylphenanthrene index (MPI): A maturity parameter based on aromatic hydrocarbons. In: Bjoroy $\mathrm{M}$, et al (Eds). Advances in Organic Geochemistry 1981. J Wiley and Sons, New York, 1983. 504-512

Radke M, Welte D H and Willsch H. Maturity parameters based on aromatic hydrocarbons: Influence of the organic matter type. Organic Geochemistry. 1986. 10: 51-63

Radke M. Application of aromatic compounds as maturity indicators in source rocks and crude oils. Marine Petroleum Geology. 1988. 5: 224-236

Santamaria-Orozco D, Horsfield B, Di Primio R, et al. Influence of maturity on distributions of benzo-and dibenzothiophenes in Tithonian source rocks and crude oils, Sonda de Campeche, Mexico. Organic Geochemistry. 1988. 28: 423-439

Schou L and Myhr M B. Sulfur aromatic compounds as maturity parameters. In Advances in Organic Geochemistry. 1987. 10: 61-66

Sivan P, Datta G C and Singh R R. Aromatic biomarkers as indicators of source, depositional environment, maturity and secondary migration in the oils of Cambay Basin, India. Organic Geochemistry. 2008. 39: 1620-1630

Strachan M G, Alexander R and Kagi R. Trimethylnaphthalenes in crude oils and sediments: Effects of source and maturity. Geochimica et Cosmochimica Acta. 1988. 52: 1255-1264

Trolio R, Grice K, Fisher S J, et al. Alkylbiphenyls and alkyldiphenylmethanes as indicators of petroleum biodegradation. Organic Geochemistry. 1999. 30: 1241-1253

van Aarssen B G K, Bastow T P, Alexander R, et al. Distributions of methylated naphthalenes in crude oils: indicators of maturity, biodegradation and mixing. Organic Geochemistry. 1999. 30: 1213- 
1227

Xiao X M, Liu D H and Fu J M. Multiple phases of hydrocarbon generation and migration in the Tazhong petroleum system of the Tarim Basin, People's Republic of China. Organic Geochemistry. 1996. 25: 191-197

Xiao X M, Song Z G, Liu D H, et al. The Tazhong hybrid petroleum system, Tarim Basin, China. Marine and Petroleum Geology. 2000. 17: $1-12$

Zhang M, Huang G $\mathrm{H}$ and $\mathrm{Hu}$ G Y. Reservoir geochemistry of the Tazhong oilfield in the Tarim Basin, China, Part I. Geochemical characteristics and genetic classification of crude oils. Chinese Journal of Geochemistry. 2006. 25: 328-331

Zhang S C and Huang H P. Geochemistry of Palaeozoic marine petroleum from the Tarim Basin, NW China: Part 1. Oil family classification. Organic Geochemistry. 2005a. 36: 1204-1214

Zhang S C, Hanson A D, Moldowan J M, et al. Paleozoic oil-source rock correlations in the Tarim Basin, NW China. Organic Geochemistry. 2000. 31: 273-286

Zhang S C, Huang H P and Xiao Z Y, et al. Geochemistry of Palaeozoic marine petroleum from the Tarim Basin, NW China: Part 2. Maturity assessment. Organic Geochemistry. 2005b. 36: 1215-1225

Zhu Y, Weng H, Su A, et al. Geochemical characteristics of Tertiary saline lacustrine oils in the Western Qaidam Basin, northwest China. Applied Geochemistry. 2005. 20: 1875-1889

(Edited by Zhu Xiuqin) 